\title{
Social behaviour and social cognition in high-functioning adolescents with autism spectrum disorder (ASD): two sides of the same coin?
}

\author{
Evelien M. Barendse ${ }^{1,2,4,5} \cdot$ Marc P. H. Hendriks $^{1,4} \cdot$ Geert Thoonen $^{3} \cdot$ Albert P. Aldenkamp $^{1,2,6} \cdot$ Roy P. C. Kessels ${ }^{4,5,7,8}$
}

Received: 14 December 2017 / Accepted: 11 May 2018 / Published online: 29 June 2018

(c) The Author(s) 2018

\begin{abstract}
Of the triad of symptoms found in autism spectrum disorder (ASD), that is, social impairments, communication difficulties and repetitive interests and behaviour, the social impairments are the most stable and common throughout the lifespan. They typically manifest themselves in abnormalities as reciprocal interactions and difficulties in the expression and recognition of emotions. Although peer interactions become especially important during adolescence, little is known about the mentalizing abilities of high-functioning adolescents with ASD. Here, we compared the mentalizing skills and emotion recognition abilities of 21 high-functioning adolescents with ASD and 21 matched controls. All adolescents had estimated above-average verbal intelligence levels. Spontaneous social abilities and task-related social abilities were measured using questionnaires, tasks and the Autism Diagnostic Observation Schedule. Results confirm social impairment in daily life situations in adolescents with ASD, but were not found on experimental tasks of social cognition. The use of more explicit cognitive or verbally mediating reasoning techniques and a lesser tendency of high-functioning adolescents with ASD to search for and use social information in natural environments are further discussed.
\end{abstract}

Keywords Autism $\cdot$ Adolescents $\cdot$ Above-average intelligence $\cdot$ Social behaviour $\cdot$ Social cognition $\cdot$ Ecological validity . Theory of mind

\section{Introduction}

Autism spectrum disorder (ASD) is a heterogeneous neurodevelopmental syndrome, which is characterized by persistent deficits in social communication and social

Handling editor: Zaimuariffudin Shukri Nordin (University Malaysia Sarawak);

Reviewers: Mansoor Channa (Quaid-e-Awam University of Engineering, Science and Technology, Pakistan), Norsiah Fauzan (University Malaysia Sarawak).

Roy P. C. Kessels

r.kessels@donders.ru.nl

1 Academic Centre for Epileptology (ACE), Kempenhaeghe, Heeze, The Netherlands

2 Department of Neurology, School for Mental Health and Neuroscience (MHeNS), Maastricht University Medical Centre, Maastricht, The Netherlands

3 Special Education School De Berkenschutse, Heeze, The Netherlands

4 Donders Institute for Brain, Cognition and Behaviour, Radboud University Nijmegen, Nijmegen, The Netherlands interaction across multiple contexts and restricted, repetitive patterns of behaviour, interest or activities (American Psychiatric Association 2013). Individuals with ASD show a large heterogeneity in phenotype, severity and type and frequency of symptoms. In addition, symptoms can change within one person over the course of development (Hill and Frith 2003; Levy et al. 2009; Wing 1997). However, as initially stated by Kanner (1943), and still relevant today: 'The outstanding, "pathognomonic", fundamental disorder is the children's inability to relate themselves in the ordinary way

5 Department of Medical Psychology, Radboud University Medical Center, Nijmegen, The Netherlands

6 Department of Electrical Engineering, University of Technology, Eindhoven, The Netherlands

7 Vincent van Gogh Institute for Psychiatry, Venray, The Netherlands

8 Department of Neuropsychology and Rehabilitation Psychology, Donders Centre for Cognition, Radboud University, Montessorilaan 3, 6525 HR Nijmegen, The Netherlands 
to people and situations from the beginning of life' (p.242). This statement is supported by recent research showing that of the triad of symptoms, social impairments are the most stable symptom not only in children, but also in adolescents, adults and elderly and across all developmental levels (Shattuck et al. 2007). As such, they are considered more central and persistent than the other core symptoms of autism (James et al. 2006; Seltzer et al. 2004; Shattuck et al. 2007). These social impairments typically manifest themselves in abnormalities in reciprocal interactions and difficulties in the expression and recognition of emotions (Bauminger 2002).

Although the social difficulties are independent of age and developmental level, their impact may disproportionally increase during adolescence (Nicpon et al. 2010; Pellicano 2010). Compared with children, adolescents are more sociable and form more complex relationship with their peers. The formation of social networks contributes to their identity development and affects their self-esteem. Adolescents are also more sensitive to acceptance and rejection by their peers (Blakemore 2008; Steinberg and Morris 2001). That is, during this developmental period, opinions and evaluations of peers become increasingly salient and many adolescents with ASD begin to notice how they differ from their peers (Burnett et al. 2009; Crone and Dahl 2012; Steinberg 2005). This is especially noticeable in high-functioning adolescents with ASD as they, more than their low-functioning counterparts, seek and initiate social interaction with peers (Bauminger et al. 2003; Hauck et al. 1995). The effects hereof may be found in the development of anxiety or mood disorders and feelings of social loneliness (the perceived lack of social involvement with peers) in high-functioning adolescents with ASD (Bauminger 2002; White et al. 2009; White and Roberson-Nay 2009). Thus, despite the general assumption of social aloofness in ASD, these reports of loneliness and the relatively high degree to which high-functioning adolescents with ASD initiate social interactions with peers (Bauminger et al. 2003) indicate that they do want to take part in more satisfying social relationships. Despite the different impact social impairments have in the different developmental stages, numerous studies have been performed on the underlying mechanisms of social impairments in younger children with ASD or in adolescents with ASD with low to average intelligence levels, but only limited research has been done on social-cognitive function in high-functioning adolescents with ASD with high-average to above-average intellectual functioning.

For social interaction to be successful, it is necessary to understand another persons' emotions, intentions, believes and knowledge (David et al. 2010). This information is needed to predict another person's behaviour and adjust one's own behaviour accordingly. The ability to impute and understand the mental states of others, and recognize that these states may differ from your own is called 'mentalizing' or having a theory of mind (ToM) (BaronCohen et al. 1985; Premack and Woodruff 1978; Vollm et al. 2006). The ability to mentalize depends on a range of both lower level mechanisms, such as face and emotion processing, gaze direction and the detection of animacy, as well as higher executive function mechanisms such as attention and working memory (see Stone and Gerrans 2006 for a review). Of these, particularly the human face and its emotional expressions play an important role in mentalizing, as they constitute an important source of information about a person's inner state. Developmental trajectories of both mentalizing and emotion recognition abilities reach near-adult levels around age eleven, with a further refinement of these skills during adolescence and across the adult lifespan (Baron-Cohen et al. 1985; see Brune and Brune-Cohrs 2006 for a review; Perner and Wimmer 1985; Rump et al. 2009).

Although mentalizing problems in individuals with ASD have been a major topic in autism research since the early 1980 s, there is still little information available on the mentalizing abilities in high-functioning adolescents with ASD. To the best of our knowledge, only two studies investigated these abilities in a group of high-functioning adolescents with either Asperger syndrome or autism (Kaland et al. 2007, 2008). Participants in these studies were 21 earlyto-late adolescents with ASD and 20 typically developing matched controls. In their first study, Kaland and colleagues (Kaland et al. 2007) used an adjusted and contextually more complex version of the Strange Stories Task (Happé 1994), whereby the participants had to make mental-state inferences versus physical state inferences in a story context. Adolescents with ASD made more errors compared with controls and had slower reaction times especially on the mental-state interference task. The authors concluded that the adolescents with ASD had more problems compared with controls in making inferences about mental states. The second study was seemingly conducted with the same participant group (Kaland et al. 2008). In this study, the performance of the participants on three different advanced theory of mind tasks, that is, The Reading the Mind in the Eyes task (Baron-Cohen et al. 2001), the Strange Stories Test (Happé 1994) and the Stories of Everyday Life (Kaland et al. 2002), were compared. The results showed that the adolescents with ASD performed worse than the typically developing controls on all three mentalizing tasks. In both studies, the authors made no direct link between the performance of the adolescents with ASD on the mentalizing tasks and their more spontaneous mentalizing abilities as for example seen on the Autism Diagnostic Observation Schedule (ADOS), a standard diagnostic measure of ASD (Lord et al. 2010), or between the tasks and the adolescents' social functioning outside the laboratory setting. 
Also important for social interaction in daily life is the ability to perceive and label expressions. However, emotion perception has also only been marginally investigated in high-functioning adolescents with ASD (Rump et al. 2009; Tracy et al. 2011), with contradicting results. Some studies showed that high-functioning adolescents with ASD were able to recognize (complex) emotional facial expressions just as fast and accurate as typically developing teens (Rump et al. 2009; Tracy et al. 2011; Jones et al. 2011), whereas other studies showed that they were less accurate than their typically developing counterparts (Kuusikko et al. 2009; Smith et al. 2010; Mazza et al. 2014; Brosnan et al. 2015; Greimel et al. 2014; Wallace et al. 2011). Only the result of one study (Wallace et al. 2011) was related to the behavioural problems these adolescents with ASD have in everyday life. They found that diminished perceptual sensitivity to sad faces was positively related to the number of social communication symptoms (as measured with the ADOS) and adaptive functioning (as measured with the Adaptive Behaviour Assessment System-II) in a group of 42 high-functioning (IQ > 80) adolescents with ASD when compared with a normal control group.

In all, little attention has been paid to social cognition in high-functioning autism, especially in adolescence, a life phase in which social skills are crucial for developing and maintaining successful relationships with peers. Both ToM and emotion recognition are important aspects of social cognition. However, while there is abundant evidence for a ToM deficit in ASD, the findings on emotion recognition are mixed. Recently, Happé and Conway (2016) even argued that although ToM deficits are a hallmark of ASD, deficits in emotion recognition are not. Furthermore, the relation between social-cognitive processes such as mentalizing and emotion perception and everyday social functioning is also unclear and especially poorly studied in high-functioning adolescents with ASD.

In the current study, we address these shortcomings by examining both mentalizing and emotion recognition abilities of high-functioning adolescents with ASD and matched typically developing controls. We aimed to relate their results with more spontaneous mentalizing skills as seen on the ADOS and their social functioning as measured with self-reports about friendship and feelings of acceptance. By doing so, we aim to get more insight into the mentalizing abilities of these high-functioning teens with ASD and find out if the skills we measure in the laboratory setting relate to the skills they are able to use in real life. Based on the existing literature, we assume to find impaired mentalizing abilities in high-functioning adolescents with ASD compared to the control group. Due to the scarcity and contradictory evidence of previous reports, emotion recognition abilities and the relation between the adolescents' social abilities in- and outside the structured setting of the laboratory were assessed in an exploratory way.

\section{Methods}

\section{Participants}

Twenty-nine high-functioning adolescents with ASD were recruited from a special secondary education school 'De Berkenschutse' located in Heeze, the Netherlands. Of this group, twenty-five adolescents fulfilled the established diagnostic criteria for autism spectrum disorder (ASD) according to the DSM-5 (APA 2013) as well as the autism algorithm cut-offs on the ADOS. Controls were twenty-nine adolescents without a history of psychological or psychiatric illness. Adolescents of both groups followed pre-university education or senior general secondary education. The groups were matched on education level, years of education, age and gender. Exclusion criteria for both groups were: an estimated verbal intelligence below 110, a diagnosis of a psychological disorder or psychiatric disease as formulated in the DSM-5 (APA 2013), such as attention-deficit and disruptive behaviour disorders, separation anxiety disorders, selective mutism, reactive attachment disorder of infancy or early childhood, anxiety disorders and mood disorders, additional factors that can influence cognitive functioning such as pathology of the central nervous system (CNS), or a significant visual or hearing impairment. Four adolescents with ASD and eight controls did not have an estimated aboveaverage verbal intelligence and were excluded. Eventually, 21 adolescents (one female) with ASD and 21 typically developing control adolescents (four females) participated in this study.

All adolescents had an estimated verbal intelligence over 109 [range ASD: 114-144; range controls: 111-144], as measured with a short version of the Wechsler Intelligence Scale for Children (WISC-III) (Campbell 1998; Donders 2001). The two groups did not differ with respect to education level, years of education, age and sex distribution. Although the groups were matched on education level and years of education, there was a significant difference in estimated verbal intelligence and full-scale intelligence levels, but effect sizes were small (Table 1). The study protocol was approved by the Medical Ethical Committee of Maastricht University Medical Centre. In accordance with the Declaration of Helsinki, informed consents were obtained from all adolescents and their parents or caregivers.

\section{Materials and procedure}

All participants who returned the informed consent form (adolescent and their parents/caregivers) were asked to fill 
Table 1 Demographic and descriptive data of the ASD and control group

\begin{tabular}{lllll}
\hline & ASD & Control & & \\
\cline { 3 - 5 } & Mean (SD) & Mean (SD) & $p$ value & Effect size $\left(\eta_{p}^{2}\right)$ \\
\hline Sex (m:f ratio) & $20: 1$ & $17: 4$ & 0.343 & \\
Age in months & $173.0(18.2)$ & $170.8(18.9)$ & 0.446 & 0.015 \\
FSIQ & $119.0(5.5)$ & $113.0(7.4)$ & 0.005 & 0.182 \\
VCI & $123.6(7.4)$ & $118.5(7.7)$ & 0.036 & 0.106 \\
ADOS & & & & \\
Communica- & $3.95(1.60)$ & - & & \\
$\quad$ tion & & & & \\
RSI & $7.10(2.51)$ & - & & \\
SBRI & $1.00(1.05)$ & - & & \\
\hline
\end{tabular}

Because we used a short version of the WISC-III, the Verbal Intelligence Quotient (VIQ) could not be calculated

$A S D$ autism spectrum disorder, VCI Verbal Comprehension Index, $F S I Q$ full-scale intelligence quotient, Control control group, ASD ASD group, RSI reciprocal social interaction, SBRI stereotyped behaviours and restricted interests

out and return questionnaires with items related to their spontaneous social functioning. The ADOS module 4 was administered to all adolescents with ASD to confirm the diagnosis and to get an impression of their more spontaneous social functioning skills as well. All participants completed two social cognition tasks: the Director Task and Emotion Recognition Task (ERT).

\section{Social functioning}

The Child Behavior Checklist and Youth Self-Report (Achenbach 1996, 1997) are questionnaires assessing the adolescent's competence, behavioural problems and emotional problems. Of these questionnaires, raw scores of the items 'Number of friends', 'Frequency of contact with friends', 'Behavior with others' and 'Behavior alone' of the Social subscale were used. Both the construct validity and criterion validity of the Child Behavior Checklist and Youth SelfReport are sufficient (Evers et al. 2007).

The Self-Perception Profile for Adolescents is a questionnaire that measures the adolescents self-concept on six domains of competence and assesses a global sense of self-worth (Treffers et al. 2002). The Self-Perception Profile for Adolescents has a good internal consistency, test-retest reliability and construct validity (Evers et al. 2007; Treffers et al. 2002). In the current study, the raw scores of the subscales 'Social acceptance' and 'Close friendships' were used.

The Autism Diagnostic Observation Schedule (ADOS) (Lord et al. 2010) module 4 is a semi-structured, standardized assessment of social, communication and language skills in adolescents and adults who are verbally fluent.
The ADOS has an excellent interrater reliability and internal consistency, and the sensitivity and specificity for ASD relative to non-spectrum disorders are also found to be excellent (Lord et al. 2000). During the ADOS assessment, activities and unstructured conversation are combined with structured situations and interview questions that offer a chance to observe a variety of behaviour. The goal of the ADOS module 4 is to determine how well the participant is able to initiate and sustain social interaction in situations with minimal structure and direction. The assessment takes 45-50 min, is recorded on video and scored afterwards by a trained examiner. The ADOS module 4 has four domain scores: (1) communication, (2) social interaction, (3) communication-social interaction total and (4) stereotyped behaviours and restricted interests. Higher scores on the domains indicate more problems on that specific domain.

\section{Social cognition: theory of mind}

The Director Task is a computerized perspective taking ToM task, which requires the participant to infer the perspective and intentions of another person (the director) and to act upon it in order to select the appropriate response (Apperly et al. 2010). This is an experimental task, which in previous research showed good discriminative validity (Dumontheil et al. 2010; Symeonidou et al. 2016). For this study, we translated this task into Dutch (for an example of the English version see Dumontheil et al. 2010).

Participants view stimuli in a cabinet with $4 \times 4$ shelves containing eight different objects. Five slots were occluded at the rear side of the cabinet. In each trial, the participant hears a director giving an instruction to move one of the eight objects in a particular direction. Next, the participant is asked to click on the referred object and drag it to the appropriate slot in the cabinet. In the Director condition, a 'director' is standing behind the cabinet, from whose perspective the contents of five slots are not visible (Fig. 1). In this condition, participants have to take into account the perspective of the director when executing the instructions. Participants were told that objects in slots with a grey background were visible only to them, whereas the other objects could be seen from either side of the cabinet. There are three kinds of instructions: (1) in experimental trials, the instruction referred to one object ('target') given from the director's point of view but would refer to another object ('distractor') if one assumed participants' perspective. As such, participants need to take the director's perspective into account to give a correct response in the experimental trials (Fig. 2a). (2) In control trials, the arrangement of the objects on the shelves was identical to the experimental trails except that an irrelevant object replaces the distractor object (e.g. the instruction referred to an object that is visible to both participant and the director; Fig. 2b). (3) Filler trial instructions 

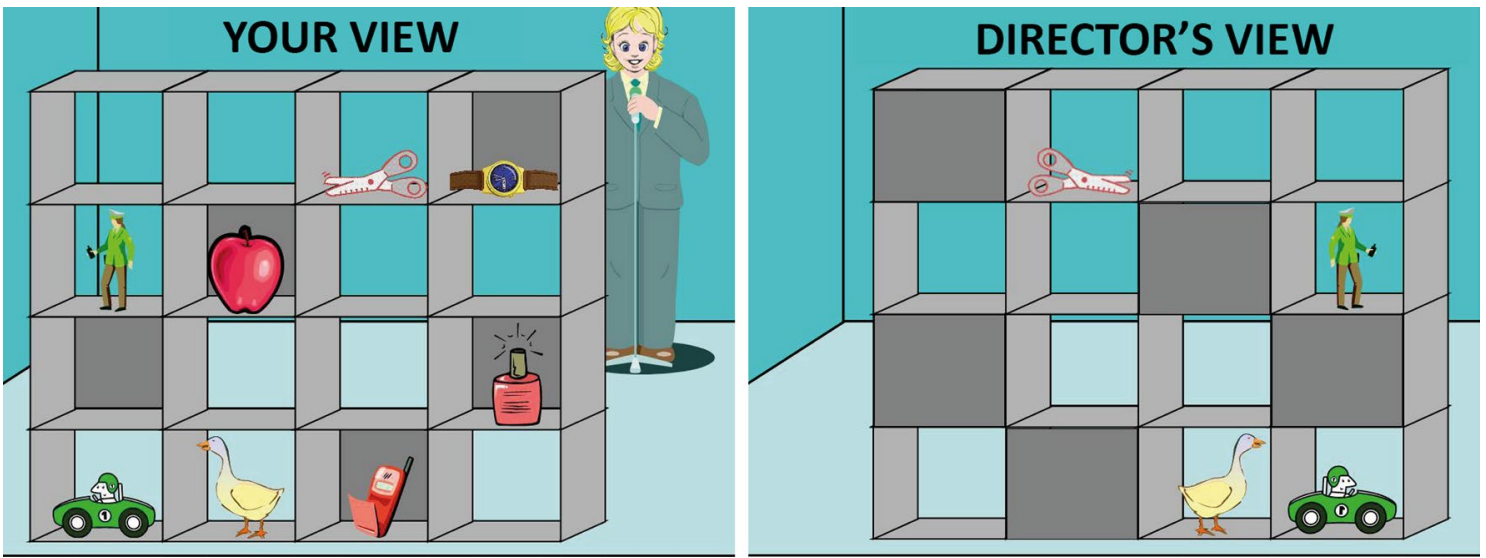

Fig. 1 Instruction screens to explain the task to participants. The cabinet on the left is shown from the participant's point of view, and the cabinet on the right is shown from the Director's point of view

refer only to objects in empty slots, that is, to objects that are visible to both the director and participant (e.g. the camera in Fig. 2). In the No-Director condition, no director was standing behind the cabinet and participants are told that the instructions only refer to objects in the clear slots; objects in slots with a grey background should be ignored (Fig. 2c, d). Other than this, the No-Director trials were identical to the Director trials and had experimental, control and filler trials.

The test consists of two sets (one for each condition) of eight different shelf-object configurations. Each stimulus was presented for $2 \mathrm{~s}$ before the first auditory instruction was given. Three auditory instructions of each $2.2 \mathrm{~s}$ were given per stimulus. After the instructions, participants had $3.6 \mathrm{~s}$ to make their response. In total, there were eight control trials, eight experimental trials and 48 filler trials in each condition (Director and No-Director). The Director condition was assessed before the No-Director condition in all participants, in order to prevent participants to apply the strategy of the No-Director condition in the Director condition.

\section{Social cognition: emotion recognition}

The ERT is a task in which dynamically morphed facial expressions are presented at different levels of intensities (Kessels et al. 2014). This is a task that in previous research showed good discriminative validity (Smith et al. 2010). Participants view short video clips which show a neutral face gradually changing into one of the six basic facial emotions; anger, disgust, fear, happiness, sadness and surprise (Ekman 1992; Ekman and Friesen 1971). After viewing the video clip, the participant has to select which emotion was shown from a list of six emotions. No time restriction was used. The version of the ERT used here included morphs from neutral to four different intensities; from 0-40, 0-60, $0-80$ to $0-100 \%$. The video clips were presented in a fixed order of four blocks containing twenty-four trials, always starting with the lower intensities after which the intensity was increased.

\section{Statistical analysis}

Data analysis was performed using the Statistical Package for Social Sciences version 20.0. Raw scores were used in all analyses, unless otherwise indicated. There was a significant difference between the two groups on VCI and FSIQ; therefore, these variables could not act as a covariate in the statistical analysis (Field 2009; Miller and Chapman 2001). Group comparisons on social behaviour, ToM and emotion recognition abilities were made using MANOVAs and mixed model MANOVAs. Correlational analyses were conducted to investigate the relationship between ToM (Director task) and emotion recognition (ERT) abilities, and between ToM/emotion recognition abilities and spontaneous social functioning (ADOS and questionnaires) in both groups separately.

\section{Results}

\section{Social functioning}

Significant differences were found on the 'Number of friends' $\left[p<0.001, \eta_{p}^{2}=0.35\right]$, the 'Frequency of contact with friends' $\left[p=0.011, \eta_{p}^{2}=0.15\right]$ and the 'Behavior (getting along) with others' $\left[p<0.001, \eta_{p}^{2}=0.36\right]$ subscales of the Child Behavior Checklist. Parents of adolescents with ASD reported that their children had fewer real friends, had less contact with their friends outside school and were less able to get along with others compared with 
Director condition
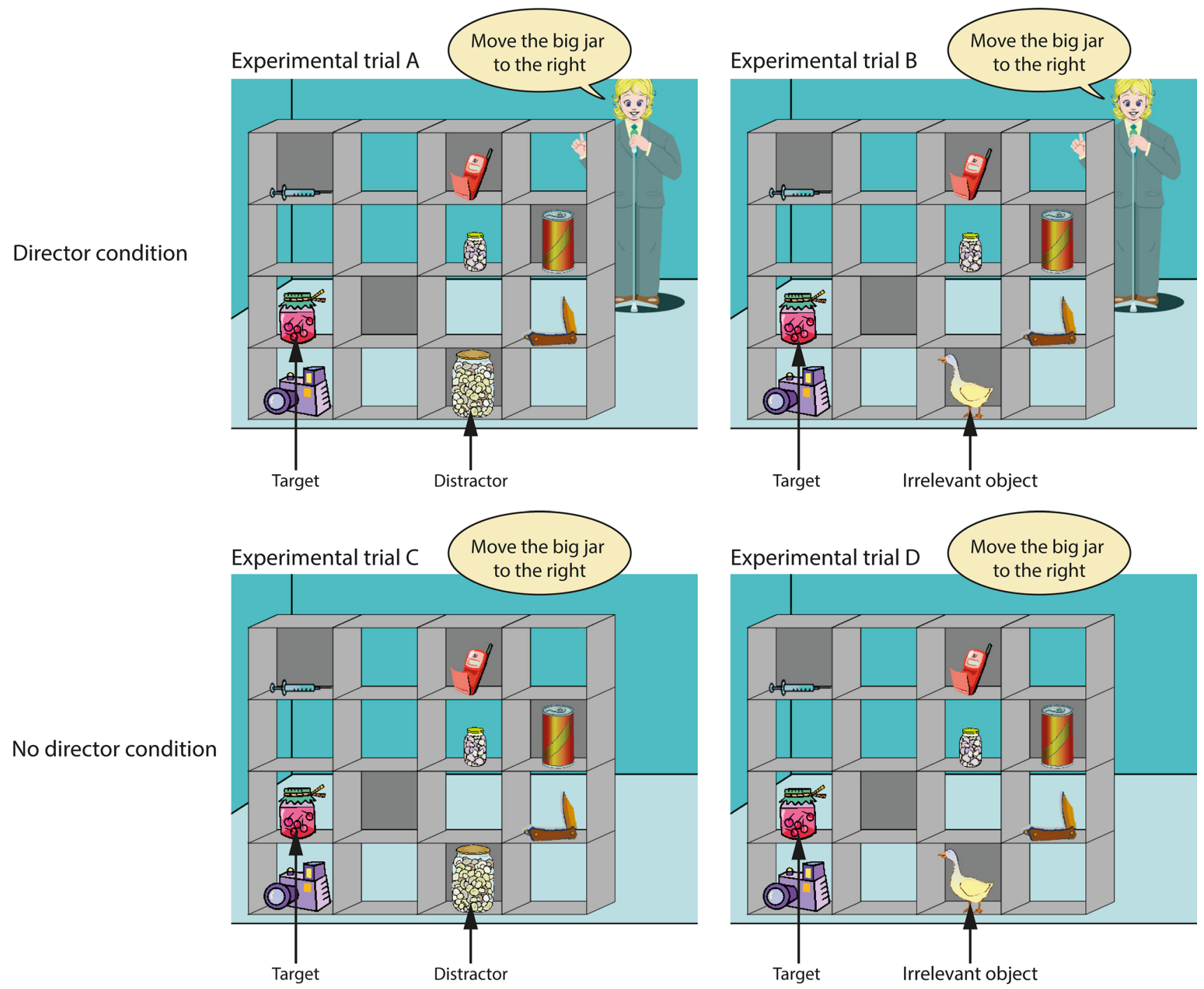

Fig. 2 Stimuli of the Director task. a b Director condition; the participant hears the instruction 'move the big jar right' from the Director. In an Experimental trial (a), if the participant does not take the director's perspective into account, he or she would move the jar with stones instead of the jar with cherries, which cannot be seen from the

the reports of the parents of adolescents in the control group. On the Youth Self-Report, a significant difference was found on the 'Behavior (getting along) with others' [ $\left.p=0.001, \eta_{p}^{2}=0.23\right]$ subscale; adolescents with ASD reported that they were less able to get along with others compared with the reports of the control group (Table 2). On the Self-Perception Profile for Adolescents, adolescents with ASD reported no significant differences on the subscales 'Social acceptation' [Control: $M=15.33$, $\mathrm{SD}=2.78$; ASD: $M=13.90, \mathrm{SD}=3.13$ ] and 'Close friendships' [Control: $M=17.14, \mathrm{SD}=2.87$; ASD $M=15.67$, $\mathrm{SD}=3.72]$, when compared with controls. directors side. In a control trial (b), the distractor is replaced by an irrelevant object (goose). c, d No-Director condition; the participant is told that instructions do not refer to items in slots with a grey background; therefore, the correct responses are the same as in de Director condition

\section{Social cognition: theory of mind}

A mixed model MANOVA with condition (Director, NoDirector) and trial type (control, experimental) as withinsubject factors and group (Control, ASD) as between-group factor revealed highly significant main effects for condition $\left[F(1,36)=16.750, p<0.0005, \eta_{p}^{2}=0.32\right]$, and trial type $\left[F(1,36)=29.366, p<0.0005, \eta_{p}^{2}=0.45\right]$, with more errors being made on the Director condition versus the No-Director condition, and more errors being made on the experimental trails than on the control trials. No overall effect of group was found $\left[F(1,36)=0.097, p=0.757, \eta_{p}^{2}=0.003\right.$ ( Fig. 3). Although not statistically significant, a trend was found for the interaction between condition and trial type 
Table 2 Social behaviour as measured with the CBCL and YSR for the ASD and control group

\begin{tabular}{|c|c|c|c|c|c|c|}
\hline \multirow[t]{2}{*}{ CBCL } & \multicolumn{2}{|l|}{ ASD } & \multicolumn{4}{|c|}{ Controls } \\
\hline & Mean & SD & Mean & SD & $p$ value & Effect size $\left(\eta_{p}^{2}\right)$ \\
\hline Number of real friends & 1.2 & 0.98 & 2.4 & 0.67 & $<0.0005$ & 0.345 \\
\hline Seeing friends outside school & 0.4 & 0.60 & 1.0 & 0.78 & 0.011 & 0.152 \\
\hline Getting along with others & 0.8 & 0.44 & 1.4 & 0.43 & $<0.0005$ & 0.362 \\
\hline Plays/works alone & 1.5 & 0.75 & 1.2 & 0.51 & 0.157 & 0.049 \\
\hline \multicolumn{7}{|l|}{$Y S R$} \\
\hline Number of real friends & 2.3 & 0.73 & 2.6 & 0.50 & 0.109 & 0.064 \\
\hline Seeing friends outside school & 0.8 & 0.77 & 1.1 & 0.85 & 0.185 & 0.045 \\
\hline Getting along with others & 1.0 & 0.31 & 1.3 & 0.36 & 0.001 & 0.230 \\
\hline Plays/works alone & 0.4 & 0.75 & 1.4 & 0.51 & 0.694 & 0.004 \\
\hline
\end{tabular}

$A S D$ autism spectrum disorder, $C B C L$ Child Behavior Checklist, YSR Youth Self-Report

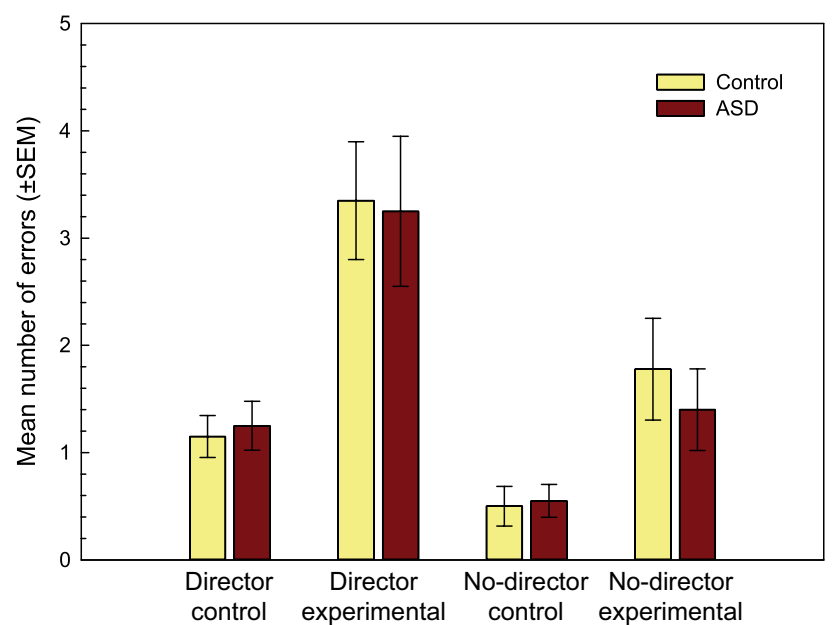

Fig. 3 Mean number of errors and standard errors of the mean on the Director Task for adolescents with autism spectrum disorder (ASD) and controls

$\left[F(1,36)=3.918, p=0.055, \eta_{p}^{2}=0.10\right]$, with slightly more errors being made on the experimental trials in the Director condition versus the No-Director condition. All other interaction effects were non-significant with $\mathrm{F}$ values below one.

\section{Social cognition: emotion recognition}

A mixed model MANOVA with emotion (anger, disgust, fear, happy, sad, surprise) and intensity $(40,60,80,100 \%)$ as within-subject factors and group (Control, ASD) as betweengroup factor showed significant main effects for emotion $\left[F(5,36)=158.608, p<0.000, \eta_{p}^{2}=0.96\right]$, and intensity $\left[F(3,38)=14.799, p<0.000, \eta_{p}^{2}=0.54\right]$. The effect of intensity showed a linear trend $[F(1,40)=36.082, p<0.000$, $\left.\eta_{p}^{2}=0.47\right]$, the higher the intensity, the higher the scores. No overall group effect was found $[F(1,40)=0.200, p=0.657$, $\left.\eta_{p}^{2}=0.01\right]$ (see Fig. 4). There was a significant interaction

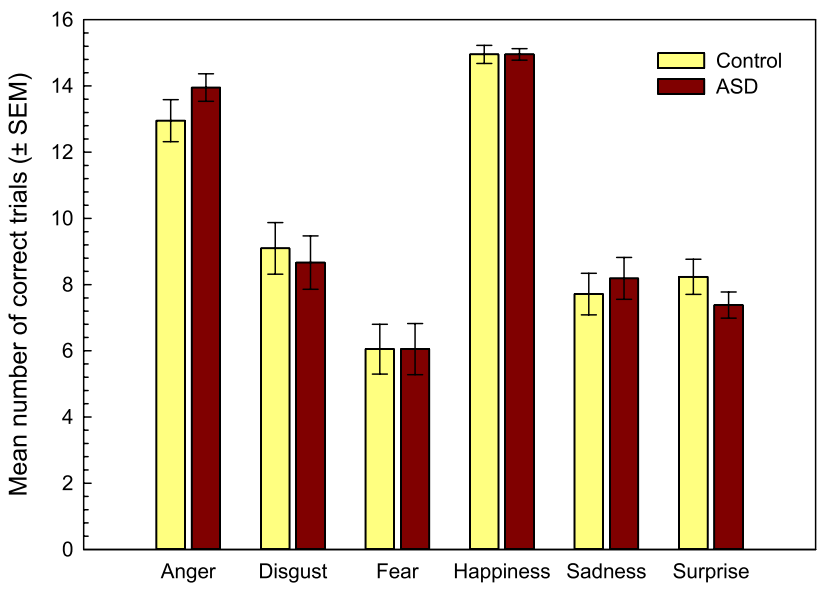

Fig. 4 Mean performance (number correct) and standard errors of the mean for the six basic emotions on the Emotion Recognition Task for the adolescents with autism spectrum disorder (ASD) and controls

effect between emotion and intensity $[F(15,26)=6.285$, $\left.p=<0.000, \eta_{p}^{2}=0.78\right]$, but no other significant interaction effects were found (all $F$ values $<1$ ). In both groups, $80 \%$ of the participants scored above the second percentile on the various emotions compared with the normative data the ERT (Kessels et al. 2014).

\section{Correlations}

Correlational analyses showed no significant correlation between intelligence (VCI, FSIQ) and the tasks (Director Task, ERT). Correlational analyses between the two tasks showed a significant correlation between the ERT and the 'Director Task - Experimental items' in the control group $[r=-0.547, p=0.013]$. In the ASD group, no significant correlations between these two tasks were found. 
Correlations between the two tasks and more spontaneous social functioning (as measured with the ADOS and items of the Child Behavior Checklist, Youth Self-Report and Self-Perception Profile for Adolescents) were not significant in either group.

\section{Discussion}

The first aim in this study was to compare mentalizing and emotion recognition abilities in high-functioning adolescents with ASD and a matched typically developing control group. We wanted to compare the groups on both their spontaneous social abilities and their task-related social abilities. Our results confirm the expected social impairments in high-functioning adolescents with ASD in daily life situations; however, we could not confirm these impairments during task performance.

In line with other studies, friendship characteristics of high-functioning adolescents with ASD differ from those of their normal developing peers (Bauminger et al. 2008a, b; Kuo et al. 2013). According to their parents, the adolescents with ASD in our study have fewer real friends and they meet their friends less often outside school compared with the control group. In general, they report that their children are less able to get along with others. Considering the three dimensions of friendship in adolescence (i.e. companionship, intimacy-trust, closeness-affection), and the fact that individuals with ASD by definition have peer difficulties (Bauminger et al. 2008b; Mazurek and Kanne 2010), we expected to find these results.

This perspective of friendship characteristics as reported by their parents, however, is not in concordance with how the adolescents with ASD describe these friendships themselves. Although they do report being less able to get along with others, their reports on social acceptance, the number of close friendships and the frequency of contact with their friends were comparable with controls. These results may be explained by differences in the definition of friendship that parents and high-functioning adolescents with ASD use. For example, Kuo and colleagues (2013) suggested that adolescents with ASD may consider peers who have similar interests to be a friend, whereas their parents may consider someone a friend only then if there is a relationship with mutual interactions and emotional interchanges. Another explanation may be that parents underestimate the adolescents' friendships because they assume that because their child has ASD, (s)he per definition would have fewer (closer) friends (Kuo et al. 2013). Considering that the adolescents with ASD in our study went to a special education school, their parents may also have less insight in the quality of the friendships, as out-of-school contact with friends mainly occurs via social media, or because adolescents in general may be inclined to a lesser extent to share their social life with their parents. However, scores on the item 'Insight in social relationships' from the ADOS show that more than $70 \%$ of the adolescents with ASD in our study have no or limited insight into the nature of social relationships and/ or his/her own role in it. In combination with the fact that all adolescents with ASD in our study scored on or above the ASD cut-off level on 'Reciprocal social interaction problems' of the ADOS, it is more likely that these adolescents with ASD use a different definition of friendship. Despite these differences in friendship definition of highfunctioning adolescents with ASD and the problems that they have in their everyday life with forming and maintaining social relationships (Scheeren et al. 2013), these problems were not confirmed on task level. Even on an advanced ToM test (Director Task) and on the recognition of more complex emotions such as 'surprise' of the ERT, where the participant has to make inferences about someone else's thoughts (Loveland et al. 1997), we do not find significant differences between adolescents with ASD and the control group.

Although most often not investigated in high-functioning adolescents with ASD, this discrepancy between social interaction problems in everyday life and the absence of deficits on neuropsychological tests of social cognition has been repeatedly reported in the ASD literature (Dahlgren and Trillingsgaard 1996; Rump et al. 2009; Russell and Hill 2001; Scheeren et al. 2013; Senju et al. 2009; Tracy et al. 2011). This apparent discrepancy could be explained by the use of compensation techniques that high-functioning individuals with ASD are often able to apply in more structured settings. By using explicit cognitive or verbally mediated reasoning techniques, in contrast to more automatic social information processing that normal developing individuals use, high-functioning people with ASD are able to pass complex emotion recognition and mentalizing tasks (Harms et al. 2010; Loveland et al. 1997; Senju et al. 2009). Also, the demands of social interaction in daily life are not as explicitly defined as, for example, task instructions of socialcognitive tests. Therefore, mental-state attribution in highfunctioning individuals with ASD may also be prompted by explicit task structure and instructions (Scheeren et al. 2013; Senju et al. 2009). A forced-choice paradigm, as in the ERT, may facilitate the recognition of facial emotions, especially if the adolescents with ASD are formally trained to identify emotions using such labels. This kind of training is often a standard component of intervention programs and may have influenced the test results of the ASD group in the current study.

Another additional explanation might be that high-functioning adolescents may not spontaneously be looking for, or detecting and using information from multiple simultaneous 
and dynamic sources in social situations, even though they might be able to comprehend them (Grossman et al. 2000; Jones et al. 2011). They may avoid making eye contact, fixate on the mouth region (Neumann et al. 2006) or miss a more general tendency to seek and initiate in social interactions. This may explain why high-functioning adolescents with ASD do not spontaneously attribute mental states, although they perform well on social functioning tasks. This is also consistent with the finding that training of mental-state attributions does not necessarily improve social adaptation in ASD (Begeer et al. 2011; Loveland et al. 1997; Ozonoff and Miller 1995; Senju 2013), although some reports show promising results (Bauminger 2002; Stichter et al. 2010) of task-related transfer to various non-trained social situations.

Both explanations, that is, the use of compensation techniques either or not in combination with the lesser tendency to search for and use social information in more natural environments, may also explain why we do not find a relationship between our tasks and daily functioning levels; they may not measure the same cognitive or psychological construct. A limitation of the current study is the relatively small sample size, which may have limited our power for detecting possible significant differences between our groups.

With respect to future recommendations, more research in larger samples is needed to investigate whether social behaviour and social cognition in high-functioning adolescents with ASD are in fact two sides of the same coin. A further challenge is to understand how exactly the aforementioned compensation in ASD takes place. That is, compensation in ASD has not received much attention so far, despite many open questions such as whether or not apparently successful compensation comes at a cost, and how compensation is modulated by the environment (see also a recent review by Livingston and Happé 2017). Moreover, it is still unclear which developing individuals with ASD will be able to acquire successful compensation in later life, as the heterogeneity in clinical presentation, course and potentially underlying neurocognitive mechanisms is large (cf. Happé and Conway 2016). Finally, the ecological validity of experimental social-cognitive paradigms, which are by definition highly structured, especially in a research setting, remains to be studied in more detail.

Acknowledgements The authors thank Renée M.H. Kessels and Mariken Dinnissen for their assistance in the data acquisition. This study was funded by special education school 'De Berkenschutse'.

\section{Compliance with ethical standards}

Conflict of interest The authors declare no conflict of interest.

Ethical approval All procedures performed in this study involving human participants were in accordance with the ethical standards and approval of the the Medical Ethical Committee of Maastricht Univer- sity Medical Center and with the 1964 Helsinki declaration and its later amendments or comparable ethical standards.

Informed consent Written informed consent was obtained from all individual participants included in the study.

Open Access This article is distributed under the terms of the Creative Commons Attribution 4.0 International License (http://creativeco mmons.org/licenses/by/4.0/), which permits unrestricted use, distribution, and reproduction in any medium, provided you give appropriate credit to the original author(s) and the source, provide a link to the Creative Commons license, and indicate if changes were made.

\section{References}

Achenbach TM (1996) Handleiding voor de Child Behavior Check List (CBCL) 4-18. Version 1/93 2001. Erasmus UMC-Sophia Kinderziekenhuis, Rotterdam

Achenbach TM (1997) Handleiding voor de Youth Self-Report (YSR). Version 8/4 2001. Erasmus UMC- Sophia Kinderziekenhuis, Rotterdam

American Psychiatric Association (2013) Diagnostic and statistical manual of mental disorders, 5th edn. APA, Washington, DC

Apperly IA, Carroll DJ, Samson D, Humphreys GW, Qureshi A, Moffitt G (2010) Why are there limits on theory of mind use? Evidence from adults' ability to follow instructions from an ignorant speaker. Q J Exp Psychol 63(6):1201-1217. https:// doi.org/10.1080/17470210903281582

Baron-Cohen S, Leslie AM, Frith U (1985) Does the autistic child have a "theory of mind"? Cognition 21(1):37-46. https://doi. org/10.1016/0010-0277(85)90022-8

Baron-Cohen S, Wheelwright S, Hill J, Raste Y, Plumb I (2001) The "Reading the Mind in the Eyes" test revised version: a study with normal adults, and adults with Asperger syndrome or highfunctioning autism. J Child Psychol Psychiatry 42(2):241-251. https://doi.org/10.1111/1469-7610.00715

Bauminger $N$ (2002) The facilitation of social-emotional understanding and social interaction in high-functioning children with autism: intervention outcomes. J Autism Dev Disord 32(4):283298. https://doi.org/10.1023/A:1016378718278

Bauminger N, Shulman C, Agam G (2003) Peer interaction and loneliness in high-functioning children with autism. J Autism Dev Disord 33(5):489-507. https://doi.org/10.1023/A:1025827427 901

Bauminger N, Solomon M, Aviezer A, Heung K, Brown J, Rogers SJ (2008a) Friendship in high-functioning children with autism spectrum disorder: mixed and non-mixed dyads. J Autism Dev Disord 38(7):1211-1229. https://doi.org/10.1007/s1080 3-007-0501-2

Bauminger N, Solomon M, Aviezer A, Heung K, Gazit L, Brown J, Rogers SJ (2008b) Children with autism and their friends: a multidimensional study of friendship in high-functioning autism spectrum disorder. J Abnorm Child Psychol 36(2):135-150. https ://doi.org/10.1007/s10802-007-9156-X

Begeer S, Gevers C, Clifford P, Verhoeve M, Kat K, Hoddenbach E, Boer F (2011) Theory of mind training in children with autism: a randomized controlled trial. J Autism Dev Disord 41(8):9971006. https://doi.org/10.1007/s10803-010-1121-9

Blakemore SJ (2008) The social brain in adolescence. Nat Rev Neurosci 9(4):267-277. https://doi.org/10.1038/nrn2353

Brosnan M, Johnson H, Grawmeyer B, Chapman E, Benton L (2015) Emotion recognition in animated compared to human stimuli in 
adolescents with autism spectrum disorder. J Autism Dev Disord 45(6):1785-1796. https://doi.org/10.1007/s10803-014-2338-9

Brune M, Brune-Cohrs U (2006) Theory of mind-evolution, ontogeny, brain mechanisms and psychopathology. Neurosci Biobehav Rev 30(4):437-455. https://doi.org/10.1016/j.neubiorev.2005.08.001

Burnett S, Bird G, Moll J, Frith C, Blakemore SJ (2009) Development during adolescence of the neural processing of social emotion. J Cogn Neurosci 21(9):1736-1750. https://doi.org/10.1162/ jocn.2009.21121

Campbell JM (1998) Internal and external validity of seven Wechsler Intelligence Scale for Children-Third Edition short forms in a sample of psychiatric inpatients. Psychol Assess 10:431-434. https:// doi.org/10.1037/1040-3590.10.4.431

Crone EA, Dahl RE (2012) Understanding adolescence as a period of social-affective engagement and goal flexibility. Nat Rev Neurosci 13(9):636-650. https://doi.org/10.1038/nrn3313

Dahlgren SO, Trillingsgaard A (1996) Theory of mind in non-retarded children with autism and Asperger's syndrome. A research note. J Child Psychol Psychiatry 37(6):759-763. https://doi. org/10.1111/j.1469-7610.1996.tb01469.x

David N, Aumann C, Bewernick BH, Santos NS, Lehnhardt FG, Vogeley K (2010) Investigation of mentalizing and visuospatial perspective taking for self and other in Asperger syndrome. J Autism Dev Disord 40(3):290-299. https://doi.org/10.1007/s1080 3-009-0867-4

Donders J (2001) Using a short form of the WISC-III: sinful or smart? Child Neuropsychol 7(2):99-103. https://doi.org/10.1076/ chin.7.2.99.3126

Dumontheil I, Apperly IA, Blakemore SJ (2010) Online usage of theory of mind continues to develop in late adolescence. Dev Sci 13(2):331-338. https://doi.org/10.1111/j.1467-7687.2009.00888.x

Ekman P (1992) An argument for basic emotions. Cogn Emot 6(34):169-200. https://doi.org/10.1080/02699939208411068

Ekman P, Friesen WV (1971) Constants across cultures in the face and emotion. J Pers Soc Psychol 17(2):124-129. https://doi. org $/ 10.1037 / \mathrm{h} 0030377$

Evers A, van Vliet-Mulder JC, Groot CJ (2007) Documentatie van tests en testresearch in Nederland, aanvulling 2007/01 (COTAN). Boom, Amsterdam

Field A (2009) Analysis of covariance, ANCOVA (GLM2), Discovering Statistics Using SPSS, 3rd edn. Sage, London, pp 397-399

Greimel E, Schulte-Ruther M, Kamp-Becker I, Remschmidt H, Herpertz-Dahlmann B, Konrad K (2014) Impairment in face processing in autism spectrum disorder: a developmental perspective. $\mathrm{J}$ Neural Transm 121(9):1171-1181. https://doi.org/10.1007/s0070 2-014-1206-2

Grossman JB, Klin A, Carter AS, Volkmar FR (2000) Verbal bias in recognition of facial emotions in children with Asperger syndrome. J Child Psychol Psychiatry 41(3):369-379. https://doi. org/10.1111/1469-7610.00621

Happé FG (1994) An advanced test of theory of mind: understanding of story characters' thoughts and feelings by able autistic, mentally handicapped, and normal children and adults. J Autism Dev Disord 24(2):129-154. https://doi.org/10.1007/BF02172093

Happé F, Conway JR (2016) Recent progress in understanding skills and impairments in social cognition. Curr Opin Pediatr 28:736742. https://doi.org/10.1097/MOP.0000000000000417

Harms MB, Martin A, Wallace GL (2010) Facial emotion recognition in autism spectrum disorders: a review of behavioral and neuroimaging studies. Neuropsychol Rev 20(3):290-322. https://doi. org/10.1007/s11065-010-9138-6

Hauck M, Fein D, Waterhouse L, Feinstein C (1995) Social initiations by autistic children to adults and other children. J Autism Dev Disord 25(6):579-595. https://doi.org/10.1007/BF02178189
Hill EL, Frith U (2003) Understanding autism: insights from mind and brain. Philos Trans R Soc Lond B Biol Sci 358(1430):281-289. https://doi.org/10.1098/rstb.2002.1209

James IA, Mukaetova-Ladinska E, Reichelt FK, Briel R, Scully A (2006) Diagnosing Aspergers syndrome in the elderly: a series of case presentations. Int J Geriatr Psychiatry 21(10):951-960. https ://doi.org/10.1002/gps.1588

Jones CR, Pickles A, Falcaro M, Marsden AJ, Happé F, Scott SK, Sauter D, Tregay J, Phillips RJ, Baird G, Simonoff E, Charman T (2011) A multimodal approach to emotion recognition ability in autism spectrum disorders. J Child Psychol Psychiatry 52(3):275285. https://doi.org/10.1111/j.1469-7610.2010.02328.x

Kaland N, Moller-Nielsen A, Callesen K, Mortensen EL, Gottlieb D, Smith L (2002) A new 'advanced' test of theory of mind: evidence from children and adolescents with Asperger syndrome. J Child Psychol Psychiatry 43(4):517-528. https://doi. org/10.1111/1469-7610.00042

Kaland N, Smith L, Mortensen EL (2007) Response times of children and adolescents with Asperger syndrome on an 'advanced' test of theory of mind. J Autism Dev Disord 37(2):197-209. https:// doi.org/10.1007/s10803-006-0152-8

Kaland N, Callesen K, Moller-Nielsen A, Mortensen EL, Smith L (2008) Performance of children and adolescents with Asperger syndrome or high-functioning autism on advanced theory of mind tasks. J Autism Dev Disord 38(6):1112-1123. https://doi. org/10.1007/s10803-007-0496-8

Kanner L (1943) Autistic disturbances of affective contact. Nerv Child 2:217-250

Kessels RPC, Montagne B, Hendriks AW, Perrett DI, De Haan EHF (2014) Assessment of perception of morphed facial expressions using the Emotion Recognition Task (ERT): normative data from healthy participants aged 8-75. J Neuropsychol 8:75-93. https:// doi.org/10.1111/jnp.12009

Kuo MH, Orsmond GI, Cohn ES, Coster WJ (2013) Friendship characteristics and activity patterns of adolescents with an autism spectrum disorder. Autism 17(4):481-500. https://doi. org/10.1177/1362361311416380

Kuusikko S, Haapsamo H, Jansson-Verkasalo E, Hurtig T, Mattila ML, Ebeling H, Jussila K, Bolte S, Moilanen I (2009) Emotion recognition in children and adolescents with autism spectrum disorders. J Autism Dev Disord 39(6):938-945. https://doi.org/10.1007/ s10803-009-0700-0

Levy SE, Mandell DS, Schultz RT (2009) Autism. Lancet 374(9701):1627-1638. https://doi.org/10.1016/S0140 -6736(09)61376-3

Livingston LA, Happé F (2017) Conceptualizing compensation in neurodevelopmental disorders: reflections from autism spectrum disorder. Neurosci Biobehav Rev 80:729-742. https://doi. org/10.1016/j.neubiorev.2017.06.005

Lord C, Risi S, Lambrecht L, Cook EH, Leventhal BL, DiLavore PC, Pickles A, Rutter M (2000) The Autism Diagnostic Observation Schedule-Generic: a standard measure of social and communication deficits associated with the spectrum of autism. J Autism Dev Disord 30(3):205-223. https://doi.org/10.1023/A:1005592401947

Lord C, Rutter M, DiLavore PC, Risi S (2010) ADOS Autisme Diagnostisch Observatie Schema Handleiding. Hogrefe, Amsterdam

Loveland KA, Tunali-Kotoski B, Chen YR, Ortegon J, Pearson DA, Brelsford KA, Gibbs MC (1997) Emotion recognition in autism: verbal and nonverbal information. Dev Psychopathol 9(3):579_ 593. https://doi.org/10.1017/S0954579497001351

Mazurek MO, Kanne SM (2010) Friendship and internalizing symptoms among children and adolescents with ASD. J Autism Dev Disord 40(12):1512-1520. https://doi.org/10.1007/s1080 3-010-1014-y 
Mazza M, Pino MC, Mariano M, Tempesta D, Ferrara M, De Berardis D, Valenti M (2014) Affective and cognitive empathy in adolescents with autism spectrum disorder. Front Hum Neurosci 8:791. https://doi.org/10.3389/fnhum.2014.00791

Miller GA, Chapman JP (2001) Misunderstanding analysis of covariance. J Abnorm Psychol 110(1):40-48. https://doi. org/10.1037/0021-843X.110.1.40

Neumann D, Spezio ML, Piven J, Adolphs R (2006) Looking you in the mouth: abnormal gaze in autism resulting from impaired topdown modulation of visual attention. Soc Cogn Affect Neurosci 1(3):194-202. https://doi.org/10.1093/scan/ns1030

Nicpon MF, Doobay AF, Assouline SG (2010) Parent, teacher, and self perceptions of psychosocial functioning in intellectually gifted children and adolescents with autism spectrum disorder. J Autism Dev Disord 40(8):1028-1038. https://doi.org/10.1007/ s10803-010-0952-8

Ozonoff S, Miller JN (1995) Teaching theory of mind: a new approach to social skills training for individuals with autism. J Autism Dev Disord 25(4):415-433. https://doi.org/10.1007/BF02179376

Pellicano E (2010) Individual differences in executive function and central coherence predict developmental changes in theory of mind in autism. Dev Psychol 46(2):530-544. https://doi.org/10.1037/ a0018287

Perner J, Wimmer H (1985) John thinks that Mary thinks that: attribution of 2nd-order beliefs by 5-year-old to 10-year-old children. J Exp Child Psychol 39(3):437-471. https://doi.org/10.1016/00220965(85)90051-7

Premack D, Woodruff G (1978) Does the chimpanzee have a theory of mind? Behav Brain Sci 4:515-526. https://doi.org/10.1017/S0140 525X00076512

Rump KM, Giovannelli JL, Minshew NJ, Strauss MS (2009) The development of emotion recognition in individuals with autism. Child Dev 80(5):1434-1447. https://doi.org/10.111 $1 / \mathrm{j} .1467-8624.2009 .01343 . x$

Russell J, Hill EL (2001) Action-monitoring and intention reporting in children with autism. J Child Psychol Psychiatry 42(3):317-328. https://doi.org/10.1111/1469-7610.00725

Scheeren AM, de Rosnay M, Koot HM, Begeer S (2013) Rethinking theory of mind in high-functioning autism spectrum disorder. J Child Psychol Psychiatry 54(6):628-635. https://doi.org/10.1111/ jcpp. 12007

Seltzer MM, Shattuck P, Abbeduto L, Greenberg JS (2004) Trajectory of development in adolescents and adults with autism. Ment Retard Dev Disabil Res Rev 10(4):234-247. https://doi. org/10.1002/mrdd.20038

Senju A (2013) Atypical development of spontaneous social cognition in autism spectrum disorders. Brain Dev 35(2):96-101. https:// doi.org/10.1016/j.braindev.2012.08.002

Senju A, Southgate V, White S, Frith U (2009) Mindblind eyes: an absence of spontaneous theory of mind in Asperger syndrome. Science 325(5942):883-885. https://doi.org/10.1126/scien ce. 1176170
Shattuck PT, Seltzer MM, Greenberg JS, Orsmond GI, Bolt D, Kring S, Lounds J, Lord C (2007) Change in autism symptoms and maladaptive behaviors in adolescents and adults with an autism spectrum disorder. J Autism Dev Disord 37(9):1735-1747. https ://doi.org/10.1007/s10803-006-0307-7

Smith MJL, Montagne B, Perrett DI, Gill M, Gallagher L (2010) Detecting subtle facial emotion recognition deficits in high-functioning autism using dynamic stimuli of varying intensities. Neuropsychologia 48(9):2777-2781. https://doi.org/10.1016/j.neuro psychologia.2010.03.008

Steinberg L (2005) Cognitive and affective development in adolescence. Trends Cogn Sci 9(2):69-74. https://doi.org/10.1016/j. tics.2004.12.005

Steinberg L, Morris AS (2001) Adolescent development. Annu Rev Psychol 52:83-110. https://doi.org/10.1146/annurev.psych.52.1.83

Stichter JP, Herzog MJ, Visovsky K, Schmidt C, Randolph J, Schultz T, Gage N (2010) Social competence intervention for youth with Asperger syndrome and high-functioning autism: an initial investigation. J Autism Dev Disord 40(9):1067-1079. https://doi. org/10.1007/s10803-010-0959-1

Stone VE, Gerrans P (2006) What's domain-specific about theory of mind? Soc Neurosci 1(3-4):309-319. https://doi. org/10.1080/17470910601029221

Symeonidou I, Dumontheil I, Chow WY, Breheny R (2016) Development of online use of theory of mind during adolescence: an eye-tracking study. J Exp Child Psychol 149:81-97. https://doi. org/10.1016/j.jecp.2015.11.007

Tracy JL, Robins RW, Schriber RA, Solomon M (2011) Is emotion recognition impaired in individuals with autism spectrum disorders? J Autism Dev Disord 41(1):102-109. https://doi.org/10.1007/ s10803-010-1030-y

Treffers PDA, Goedhardt AW, Veerman JW, Van den bergh BRH, Ackaert L, de Rycke L (2002) Handleiding Competentie Belevingsschaal voor Adolescenten. Swets Test Publishers, Lisse

Vollm BA, Taylor AN, Richardson P, Corcoran R, Stirling J, McKie S, Deakin JF, Elliott R (2006) Neuronal correlates of theory of mind and empathy: a functional magnetic resonance imaging study in a nonverbal task. Neuroimage 29(1):90-98. https://doi. org/10.1016/j.neuroimage.2005.07.022

Wallace GL, Case LK, Harms MB, Silvers JA, Kenworthy L, Martin A (2011) Diminished sensitivity to sad facial expressions in high functioning autism spectrum disorders is associated with symptomatology and adaptive functioning. J Autism Dev Disord 41(11):1475-1486. https://doi.org/10.1007/s10803-010-1170-0

White SW, Roberson-Nay R (2009) Anxiety, social deficits, and loneliness in youth with autism spectrum disorders. J Autism Dev Disord 39(7):1006-1013. https://doi.org/10.1007/s10803-009-0713-8

White SW, Oswald D, Ollendick T, Scahill L (2009) Anxiety in children and adolescents with autism spectrum disorders. Clin Psychol Rev 29(3):216-229. https://doi.org/10.1016/j.cpr.2009.01.003

Wing L (1997) The autistic spectrum. Lancet 350(9093):1761-1766. https://doi.org/10.1016/S0140-6736(97)09218-0 